\title{
Avaliação de lotes residenciais sob a perspectiva da sustentabilidade ambiental: um estudo aplicado à cidade de Maringá-PR, Brasil.
}

Evaluation of residential lots from the perspective of environmental sustainability: a study applied to the city of Maringá-PR, Brazil.

Evaluación de lotes residenciales desde la perspectiva de la sostenibilidad ambiental: un estudio aplicado a la ciudad de Maringá-PR, Brasil.

Mario Henrique Bueno Moreira Callefi

Mestre em Engenharia Urbana, UEM, Brasil. mariocallefi@gmail.com

\author{
José Luiz Miotto \\ Professor Doutor, UEM, Brasil. \\ jlmiotto@uem.br \\ Rafaela Vilas Boas Silva \\ Rafaelavbs@gmail.com
}

Mestre em Engenharia Urbana, UEM, Brasil. 


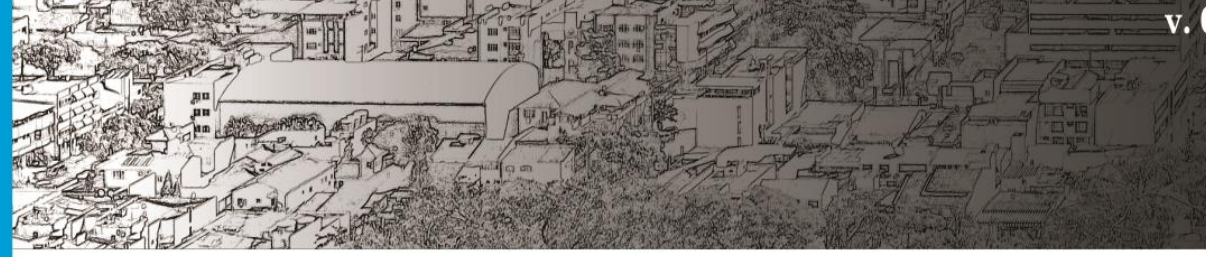

\section{Revista Nacional de}

Gerenciamento de Cidades

\section{INTRODUÇÃO}

A temática da sustentabilidade vem ganhando cada vez mais importância no cenário global, relacionando-se, de acordo com Elkington (2011), com a maneira que ações atuais são planejadas, com vistas a garantir que não exista limitação na capacidade de as gerações futuras escolherem determinadas opções que nos dias atuais são disponíveis, abrangendo os aspectos econômicos, sociais e ambientais.

Com o avanço dessa temática, cresce também a preocupação com o desenvolvimento sustentável das cidades modernas. Sendo assim, se verifica a necessidade do uso racional de recursos naturais e do ambiente ecológico. Desta forma, busca-se garantir que os ecossistemas urbanos tenham capacidade de se reparar e de se reproduzir, já que qualquer modificação no ciclo natural pode resultar em graves problemas para a sobrevivência dos seres humanos e dos ecossistemas urbanos (LU; KE, 2018).

Por ser tratar de um importante agente de transformação do meio ambiente e com relações indissociáveis com a sustentabilidade, a construção civil insere-se de maneira marcante neste contexto. Esse setor é considerado um dos maiores agentes de transformação de ambientes naturais em ambientes construídos, consumindo grandes quantidades de recursos naturais e gerando um excessivo volume de resíduos e de poluentes (JOHN, 2000). Desta forma, devido ao caráter impactante desse setor no meio ambiente, passa a ser necessário o desenvolvimento de medidas para avaliar as questões ligadas à sustentabilidade das edificações.

Neste sentido foram desenvolvidas as certificações das construções sustentáveis, que podem ser definidas como sendo sistemas que avaliam diferentes características das edificações, de modo a investigar o seu desempenho sustentável, abrangendo a análise do consumo de energia e os impactos ambientais gerados no decorrer das fases de uma construção (AWADH, 2017). As certificações das edificações sustentáveis possuem atualmente um foco maior nas questões ligadas à ocupação urbana e às características da edificação. Já os aspectos relacionados com a sustentabilidade de lotes urbanos em geral são tratados de forma superficial (KOSANOVIĆ; FIKFAK, 2016).

Kosanović e Fikfak (2016) apontam a necessidade de se levar em conta os aspectos ligados ao lote urbano e a investigação de sua pré-disposição para a implantação de uma edificação sustentável, promovendo melhores condições de vida aos usuários. Jung e Lee (2012) destacam a importância do desenvolvimento de ferramentas para a avaliação ambiental de lotes, já que elas otimizam o processo de escolha da localização de empreendimentos, contribuindo assim para tornar o desenvolvimento urbano mais ambientalmente adequado.

Nesse contexto, a presente pesquisa tem como objetivo geral avaliar lotes destinados à implantação de habitações unifamiliares sob a perspectiva da sustentabilidade ambiental, baseando-se nos critérios contidos nas certificações das construções sustentáveis e de outros indicadores relacionados com a sustentabilidade ambiental de lotes urbanos. 


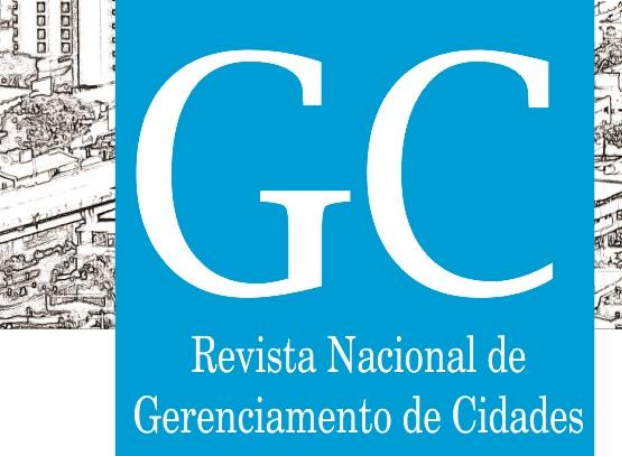

\section{MATERIAIS E MÉTODOS}

Considerando o objetivo principal desta pesquisa, nesta seção serão apresentadas as etapas metodológicas necessárias à sua concretização. Para realização da pesquisa foram definidas as etapas do método e construiu-se o fluxograma apresentado na Figura 1. No total são 11 atividades, agrupadas em três etapas: (a) definição dos indicadores e critérios; (b) aplicação do método AHP; e (c) avaliação dos lotes.

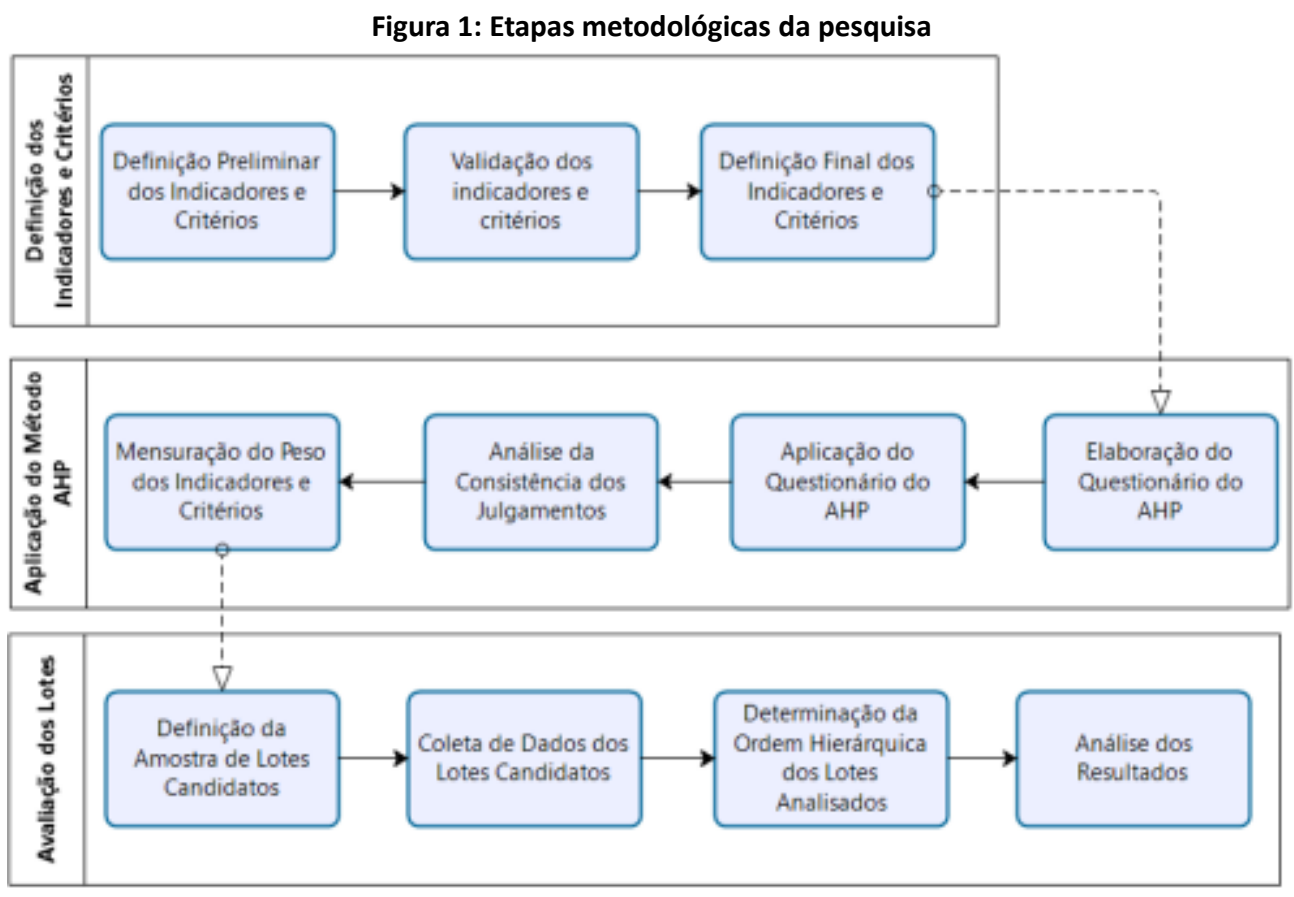

Fonte: Autores, 2020.

Na primeira etapa do método foi realizado um levantamento bibliográfico definindo-se os critérios que compõem os indicadores preliminares, baseando-se principalmente nas especificações contidas nas certificações das construções sustentáveis (Selo Casa Azul, LEED e Processo AQUA) e nos indicadores e critérios para avaliação da sustentabilidade de lotes apresentados por Azouz e Galal (2016), Kosanović e Fikfak (2016).

Alguns dos critérios identificados na bibliografia possuíam requisitos que não se adequavam à realidade da cidade de Maringá-PR e outros critérios eram abordados de maneira superficial, não especificando requisitos ou descrições que permitissem utilizá-los para a avaliação dos parâmetros por eles abrangidos. Para resolver essa dificuldade, foram propostos requisitos que tornariam o critério mais alinhado com o tema da pesquisa. Além disso, procurou-se definir os requisitos dos critérios de forma a dividi-los em escalas de créditos, permitindo que em casos 


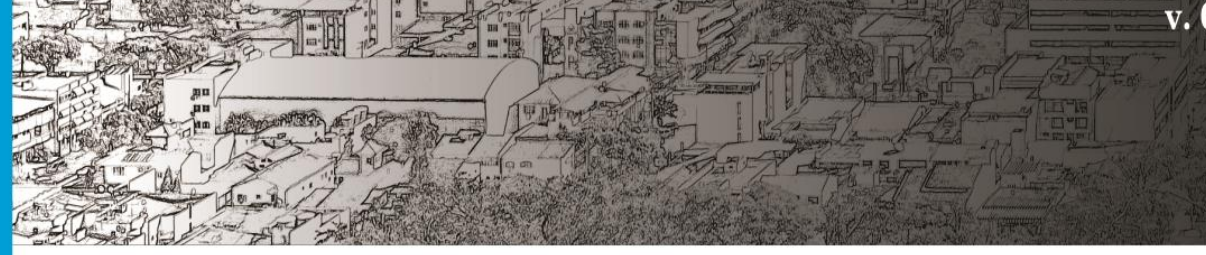

\section{Revista Nacional de}

Gerenciamento de Cidades

em que o lote analisado não satisfaça totalmente todos os requisitos de um critério, possam ser atribuídos uma quantidade menor de créditos. Esse conceito de créditos parciais é utilizado frequentemente nas certificações LEED.

Nesta etapa preliminar foram definidos 10 critérios, agrupados em três indicadores:

- Indicador de Condições Ambientais: abrange os critérios de Áreas Suscetíveis a Alagamento, Áreas Suscetíveis a Deslizamento de Solo, Distância de Corpos d'Água e Distância de unidades de conservação e de Áreas de Proteção Permanente (APP).

- Indicador de Características do Entorno: abrange os indicadores de Impactos na Qualidade do Entorno, Infraestrutura básica e Brownfields.

- Indicador de Preservação Ambiental: abrange os critérios de Coleta de Resíduos Sólidos e Recicláveis e Necessidade de Movimentação de Solo.

A segunda etapa consistiu na validação dos indicadores e critérios. A validação foi realizada com base nos princípios do método AHP (Analytic Hierarchy Process). Nesse método, de acordo com Saaty (2008), os julgamentos dos critérios são realizados por especialistas, sendo eles de áreas de conhecimento diversificadas, mas com refinados conhecimentos na área da pesquisa, para inicialmente validar os indicadores e critérios propostos.

Segundo Yang, Li e Yao (2010), o número de especialistas não precisa ser elevado, desde que a quantidade escolhida seja suficiente para garantir que a Razão Consistência (RC) seja menor que o valor de 0,1. Já que a definição do número de especialistas é diversificada nas pesquisas consultadas e tendo como principal preocupação que os julgamentos realizados estejam dentro da $\mathrm{RC}$ recomendada, definiu-se uma quantidade de sete especialistas para a presente pesquisa, composta da seguinte maneira: um especialista da área de engenharia civil, um da geografia, dois da arquitetura, um do mercado imobiliário e dois da Prefeitura Municipal de Maringá.

Outro ponto é que normalmente no método AHP são realizadas reuniões com todos os especialistas juntos, para a definição e comparação dos critérios. Essa reunião não foi realizada devido à dificuldade de reunir a equipe de especialistas, já que não foi possível definir um horário ou local que fosse viável para todos. Além disso, um dos especialistas residia na cidade de Curitiba-PR.

Após a aprovação da pesquisa junto ao COPEP (Comitê Permanente de Ética em Pesquisa com Seres Humanos) da Universidade Estadual de Maringá, foi realizada a segunda etapa metodológica. Essa etapa consiste na validação dos indicadores e critérios. Nessa etapa foi entregue um questionário para os especialistas, de modo que pudessem realizar os julgamentos de validação dos critérios e para o apontamento de possíveis modificações na organização dos indicadores ou da inclusão de novos critérios que poderiam compor a pesquisa.

A segunda etapa dos procedimentos metodológicos foi composta de quatro atividades: elaboração do questionário do AHP; aplicação do questionário do AHP; análise da consistência dos julgamentos; e, por último, o cálculo do peso dos indicadores e critérios. 


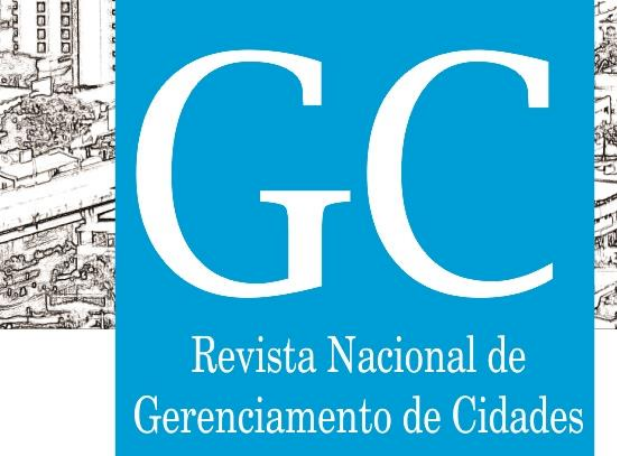

Quadro 1: Indicador 1 - Características do Entorno

\begin{tabular}{|c|c|c|}
\hline Critério & Descrição & Baseado em: \\
\hline $\begin{array}{c}\text { Áreas } \\
\text { Suscetíveis a } \\
\text { Alagamento }\end{array}$ & $\begin{array}{l}\text { Para este critério é observada a ocorrência de alagamentos em áreas próximas ao } \\
\text { lote. O seguinte requisito é especificado: } \\
\text { - É necessário que não exista a ocorrência de alagamento, considerando } \\
\text { um raio de distância de } 400 \mathrm{~m} \text { do lote analisado, no período dos últimos três } \\
\text { anos - } 100 \% \text { dos créditos. }\end{array}$ & $\begin{array}{c}\text { LEED BD+C v4 } \\
(\text { USGBC } \\
(2014))\end{array}$ \\
\hline $\begin{array}{c}\text { Áreas } \\
\text { Suscetíveis a } \\
\text { Deslizamento } \\
\text { de Solo }\end{array}$ & $\begin{array}{l}\text { Para este critério é observada a ocorrência de deslizamentos de solo em áreas } \\
\text { próximas ao lote. O seguinte requisito é especificado: } \\
\text { - É necessário que não exista a ocorrência de deslizamento de solo, } \\
\text { considerando um raio de distância de } 400 \text { m do lote analisado, no período dos } \\
\text { últimos três anos - } 100 \% \text { dos créditos. }\end{array}$ & $\begin{array}{c}\text { Azouz e Galal } \\
\text { (2016) }\end{array}$ \\
\hline $\begin{array}{l}\text { Impactos } \\
\text { Existentes no } \\
\text { Entorno }\end{array}$ & $\begin{array}{l}\text { Este critério avalia a existência de fatores que sejam prejudiciais ao bem-estar, } \\
\text { segurança e saúde dos usuários, como a presença de rodovias, aeroportos e de } \\
\text { zonas industriais que podem gerar níveis de ruído prejudicais à saúde. O seguinte } \\
\text { requisito é especificado: } \\
\text { - É necessário que nenhum desses fatores esteja presente no raio de } \\
\text { distância de até } 2500 \text { m do lote analisado - } 100 \% \text { dos créditos. }\end{array}$ & $\begin{array}{c}\text { Selo Casa } \\
\text { Azul (John e } \\
\text { Prado (2010)) }\end{array}$ \\
\hline $\begin{array}{l}\text { Infraestrutura } \\
\text { básica }\end{array}$ & $\begin{array}{l}\text { Este critério avalia a existência de elementos de infraestrutura básica na malha } \\
\text { urbana nas proximidades do lote. Para se alcançar } 100 \% \text { dos créditos para este } \\
\text { critério é necessário que estejam presentes os seguintes elementos de } \\
\text { infraestrutura básica nas proximidades do lote: Pavimentação; Energia elétrica; } \\
\text { lluminação pública; Rede de abastecimento de água potável; Sistema de } \\
\text { esgotamento sanitário. }\end{array}$ & $\begin{array}{l}\text { Selo Casa } \\
\text { Azul (John e } \\
\text { Prado (2010)) } \\
\text { e } \\
\text { Azouz e Galal } \\
\quad(2016) \\
\end{array}$ \\
\hline Brownfields & $\begin{array}{l}\text { Este critério avalia a presença de brownfields na envoltória dos lotes. Os seguintes } \\
\text { requisitos são especificados: } \\
\text { - É necessário que o lote esteja localizado no raio de até } 400 \mathrm{~m} \text { de antigas } \\
\text { áreas de brownfields para as quais foram implantadas medidas adequadas } \\
\text { para evitar a contaminação do solo ou de águas subterrâneas - } 100 \% \text { dos } \\
\text { créditos. } \\
\text { - Ou esteja localizado no raio de até } 400 \mathrm{~m} \text { de atuais áreas de brownfields } \\
\text { e para as quais foram implantadas medidas adequadas para evitar a } \\
\text { contaminação do solo ou de águas subterrâneas - } 75 \% \text { dos créditos. } \\
\text { - Ou não esteja localizado no raio de até } 400 \mathrm{~m} \text { de antigas ou atuais áreas } \\
\text { de brownfields }-50 \% \text { dos créditos. }\end{array}$ & $\begin{array}{l}\text { LEED BD+C v4 } \\
\quad(\text { USGBC } \\
(2014)) \text { e } \\
\text { Azouz e Galal } \\
\quad(2016)\end{array}$ \\
\hline
\end{tabular}

Fonte: Autores, 2020. 

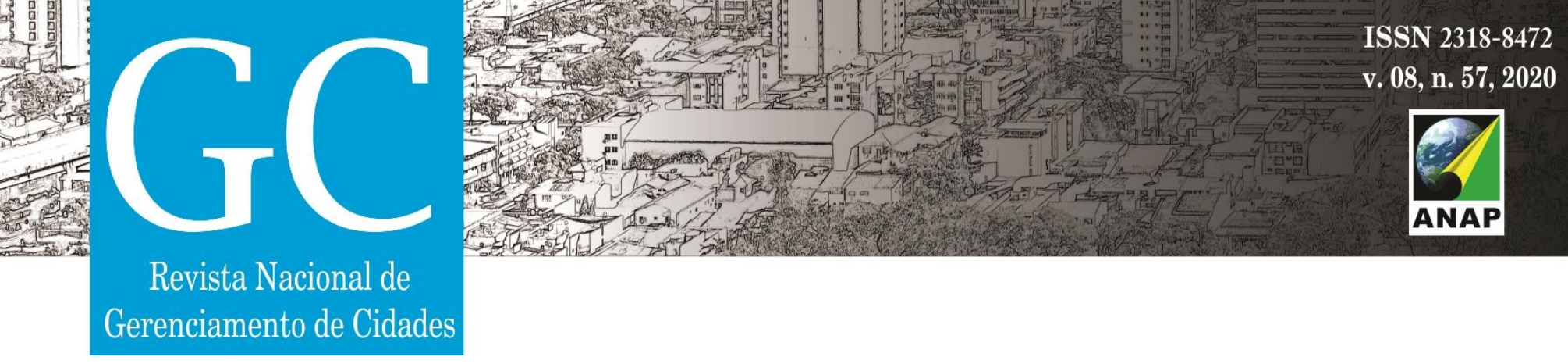

\begin{tabular}{|c|c|c|}
\hline Critério & & \\
\hline $\begin{array}{l}\text { Coleta de Resíduos } \\
\text { Sólidos e Recicláveis }\end{array}$ & $\begin{array}{l}\text { Este critério avalia se o lote é atendido por serviços de coleta } \\
\text { de resíduos sólidos urbanos e recicláveis e se existem Pontos } \\
\text { de Entrega Voluntário (PEV) de resíduos nas proximidades do } \\
\text { lote. Sendo os seguintes requisitos especificados: } \\
\text { - Caso o lote seja atendido por serviços de coleta de } \\
\text { resíduos sólidos urbanos e recicláveis e que exista algum } \\
\text { ponto de Ponto de Entrega Voluntário (PEV) de resíduos } \\
\text { no raio de até } 1.000 \text { m de distância do lote - } 100 \% \text { dos } \\
\text { créditos; } \\
\text { - Ou que o lote seja atendido por serviços coleta de } \\
\text { resíduos sólidos urbanos e recicláveis - } 75 \% \text { dos } \\
\text { créditos; } \\
\text { - Ou que o lote seja atendido apenas por serviços de } \\
\text { coleta de resíduos sólidos urbanos - } 50 \% \text { dos créditos. }\end{array}$ & $\begin{array}{l}\text { LEED ND v4 (USGBC } \\
\text { (2017)), Kosanović e Fikfak } \\
\text { (2016) e Processo AQUA } \\
\text { (Fundação Vanzolini e } \\
\text { Cerway (2016)) }\end{array}$ \\
\hline $\begin{array}{l}\text { Necessidade de } \\
\text { Movimentação de } \\
\text { Solo }\end{array}$ & $\begin{array}{l}\text { Este critério avalia a necessidade de movimentação de solo } \\
\text { para a implantação de um empreendimento futuro. Sendo } \\
\text { especificado o seguinte requisito: } \\
\text { - Caso não exista uma significativa demanda de } \\
\text { movimentação de solo para a construção de uma futura } \\
\text { residência no local, ou seja, se identificará a necessidade } \\
\text { da realização de cortes e aterros no lote avaliado-100\% } \\
\text { dos créditos. }\end{array}$ & $\begin{array}{c}\text { Selo Casa Azul (John e } \\
\text { Prado (2010)) e Processo } \\
\text { AQUA (Fundação Vanzolini } \\
\text { e Cerway (2016)) }\end{array}$ \\
\hline $\begin{array}{l}\text { Espaços } \\
\text { Compartilhados para } \\
\text { Produção de } \\
\text { Alimentos }\end{array}$ & $\begin{array}{l}\text { Este critério avalia a existência de jardins ou hortas } \\
\text { comunitárias para produção local de alimentos em áreas } \\
\text { próximas ao lote. Sendo especificado o seguinte requisito: } \\
\text { - Caso exista no mínimo um jardim ou horta } \\
\text { comunitária em um raio de até } 2.000 \mathrm{~m} \text { de distância do } \\
\text { lote }-100 \% \text { dos créditos. }\end{array}$ & LEED ND v4 (USGBC (2017)) \\
\hline $\begin{array}{c}\text { Distância de Corpos } \\
\text { d'Água }\end{array}$ & $\begin{array}{l}\text { Considerando as diretrizes imposta pela Lei Nacional } 12.651 \\
\text { de } 2012 \text {, que dispõe sobre a proteção da vegetação nativa, } \\
\text { este critério avalia a existência de corpos d'água nas } \\
\text { proximidades do lote avaliado, sendo especificados os } \\
\text { seguintes requisitos para se alcançar } 100 \% \text { dos créditos: } \\
\text { - O lote deve estar a pelo menos } 30 \text { m de distância } \\
\text { de qualquer corpo d'água que tenha menos de } 10 \mathrm{~m} \text { de } \\
\text { largura; } \\
\text { - O lote deve estar a pelo menos } 50 \mathrm{~m} \text { de distância } \\
\text { de qualquer corpo d'água que tenha de } 10 \text { a } 50 \mathrm{~m} \text { de } \\
\text { largura. }\end{array}$ & $\begin{array}{l}\text { LEED BD+C v4 (USGBC } \\
\text { (2014)) e Lei Nacional } \\
12.651 \text { de } 2012 \text { (Brasil } \\
\text { (2012)) }\end{array}$ \\
\hline
\end{tabular}

Fonte: Autores, 2020.

Por meio dos julgamentos dos especialistas se realizou o cálculo do peso dos indicadores e critérios, conforme se apresenta na Tabela 1. 
Tabela 1: Pesos dos indicadores e critérios

\begin{tabular}{lcc}
\hline \multicolumn{1}{c}{ Descrição } & Peso & Créditos \\
\hline \multicolumn{1}{c}{ Indicador 1 - Características do Entorno } & $\mathbf{0 , 6 0 3 2}$ & - \\
\hline Áreas Suscetíveis a Alagamento & 0,1309 & 13 \\
Áreas Suscetíveis a Deslizamento de Terra & 0,1692 & 17 \\
Impactos Existentes no Entorno & 0,0944 & 9 \\
Infraestrutura básica & 0,1547 & 16 \\
Brownfields & 0,054 & 5 \\
\hline & 0,3968 & - \\
\hline Coleta de Resíduos Sólidos e Recicláveis & 0,0701 & 7 \\
Necessidade de Movimentação de Terra & 0,0539 & 5 \\
Espaços Compartilhados para Produção de Alimentos & 0,025 & 3 \\
Distância de Corpos d'Água & 0,1361 & 14 \\
Distância de Unidades de Conservação e de Áreas de Proteção Permanente (APP) & 0,1117 & 11 \\
\hline
\end{tabular}

Fonte: Autores, 2020.

A partir dos dados da Tabela 1 pode-se observar que o indicador Características do Entorno apresenta o maior peso e, nesse conjunto, os três critérios com maior peso são: Áreas Suscetíveis a Deslizamento de Solo (16,92\%); Infraestrutura Básica (15,47\%); Distância de Corpos d'Água (13,61\%). Para simplificação dos cálculos, no sistema de avaliação proposto considerouse o peso calculado multiplicado por 100 , de modo que os créditos para cada critério sejam números inteiros, conforme Tabela 1. Estabelecidas as quantidades de créditos para cada critério, foi possível iniciar a avaliação dos lotes que compõem a amostra, seguindo os requisitos apresentados nos Quadros 1 e 2.

Critério 1 - Áreas Suscetíveis a Alagamento

Elaborada a proposta preliminar da ferramenta de avaliação, constituída por indicadores e critérios, os especialistas foram consultados para a sua validação. Os resultados são apresentados nos Quadros 1 e 2. Com a análise dos dados relativos ao primeiro critério, se verificou a existência de ocorrências de alagamentos no entorno dos lotes analisados, entre os anos de 2015 e 2017. Nesse período, segundo dados da plataforma do Corpo de Bombeiros do Paraná (2018), houve 29 ocorrências de alagamentos na cidade de Maringá - PR.

Duas das ocorrências de alagamentos ocorreram em um raio de distância menor que $400 \mathrm{~m}$ de algum dos lotes avaliados. Trata-se dos lotes 4 (R. Saint Hilaire, 2182) e 13 (R. Tiradentes, 307), representados na Figura 2, nos quais foram identificadas ocorrências de alagamento em suas proximidades. Desse modo, somente os lotes 4 e 13 não receberam nenhum crédito para este 


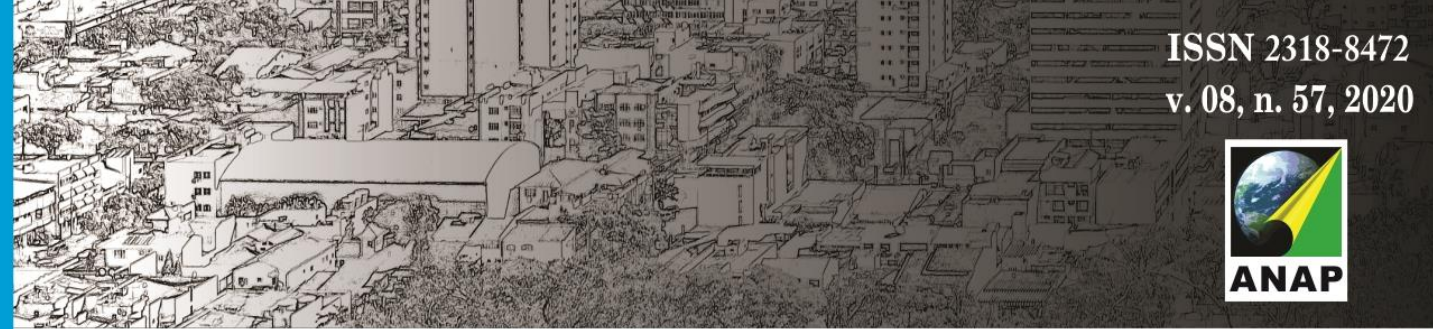

Revista Nacional de

Gerenciamento de Cidades

ocorreu a um raio de distância menor que $400 \mathrm{~m}$ de algum dos lotes avaliados. Dessa maneira, todos os lotes avaliados receberam $100 \%$ dos créditos para este critério, ou seja, 8 créditos.

\section{Critério 3 - Impactos Existentes no Entorno}

No terceiro critério se verificou a existência de fatores - no raio de $2.500 \mathrm{~m}$ de distância do lote analisado - que sejam prejudiciais ao bem-estar, segurança e saúde dos usuários, como a presença de rodovias, aeroportos e de zonas industriais que podem gerar níveis de ruído prejudiciais à saúde humana.

A partir da coleta dos dados necessários se constatou que em todos os lotes analisados existia algum dos fatores citados acima em suas proximidades, sendo assim, todos eles não alcançaram nenhum crédito neste critério. Essa realidade pode ser explicada uma vez que, para praticamente todos os pontos que podem ser selecionados dentro da malha urbana de Maringá, existe alguma rodovia no raio de $2.500 \mathrm{~m}$.

\section{Critério 4 - Infraestrutura Básica}

No quarto critério se avaliou a existência de elementos de infraestrutura básica nas proximidades dos lotes analisados, abrangendo os seguintes elementos: pavimentação, energia elétrica, iluminação pública, rede de abastecimento de água potável e sistema de esgotamento sanitário.

A partir da coleta de dados se verificou que em todos os lotes existiam os fatores exigidos pelo critério em questão. Dessa forma, todos os lotes receberam $100 \%$ dos créditos, ou seja, 16 créditos.

\section{Critério 5 - Brownfields}

No quinto critério se verificou a existência de brownfields na envoltória dos lotes analisados. Não foi possível avaliar se algum dos lotes está localizado nas proximidades de antigas áreas de brownfields, devido à indisponibilidade de dados que poderiam comprovar esse fato.

A partir da análise dos lotes sob avaliação, se verificou que apenas o lote 7 (Travessa Indianópolis, 224) estava localizado próximo de alguma área atual de brownfield. Esse local pode ser considerado uma brownfield, já que está localizado nas proximidades de uma antiga pista de decolagem e pouso de avião, que pertencia ao Aeroporto Gastão Vidigal, o qual foi desativado no início da década de 2000.

Dessa forma, apenas o lote 7 alcançou 75\% dos créditos neste critério, ou seja, 3,75 créditos. Para o restante dos lotes se admitiu que não haviam brownfields nas proximidades, atribuindose a esses lotes $50 \%$ dos créditos, ou seja, 2,5 créditos. 


\section{Revista Nacional de}

Gerenciamento de Cidades

Verifica-se, partir dos dados apresentados na Tabela 2 e na Figura 5, que metade dos 36 lotes avaliados obtiveram a mesma pontuação, ou seja, alcançaram 90,5 créditos. Por outro lado, os lotes com piores resultados foram os lotes 4 (R. Saint Hilaire, 2182) e 13 (R. Tiradentes, 307), os quais alcançaram 77,5 e 74,5 créditos, respectivamente.

Com base nos dados desta amostra, em que metade dos lotes analisados alcançou mais de $90 \%$ dos créditos, é possível observar que os lotes urbanos analisados na cidade Maringá - PR se adéquam aos princípios da sustentabilidade ambiental, considerando-se obviamente as limitações impostas na ferramenta de avaliação estabelecida neste trabalho, ou seja, contemplando-se dois indicadores e 10 critérios.

Complementando esta avaliação, é possível formular o seguinte questionamento: os valores de comercialização e venais desses lotes são determinados levando-se em conta os aspectos da sustentabilidade?

Para isso, primeiramente foram pesquisados os valores de comercialização e venais de cada um dos lotes. $\mathrm{O}$ valor de comercialização se refere ao preço que a imobiliária estipula para o lote, considerando as características e condições do seu entorno. Por sua vez, o valor venal aquele estabelecido pela Planta de Valores Genéricos de Edificações e de Terrenos da cidade de Maringá - PR, a partir da Lei Complementar 1.106/2017, e se refere ao valor utilizado como base para o cálculo do IPTU e outras negociações imobiliárias.

Na Figura 6 se apresenta o gráfico de dispersão envolvendo o total de créditos alcançados por cada lote na avaliação e o valor de comercialização. A Figura 7 traz a relação entre o total de créditos alcançados por cada lote e os seus respectivos valores venais.

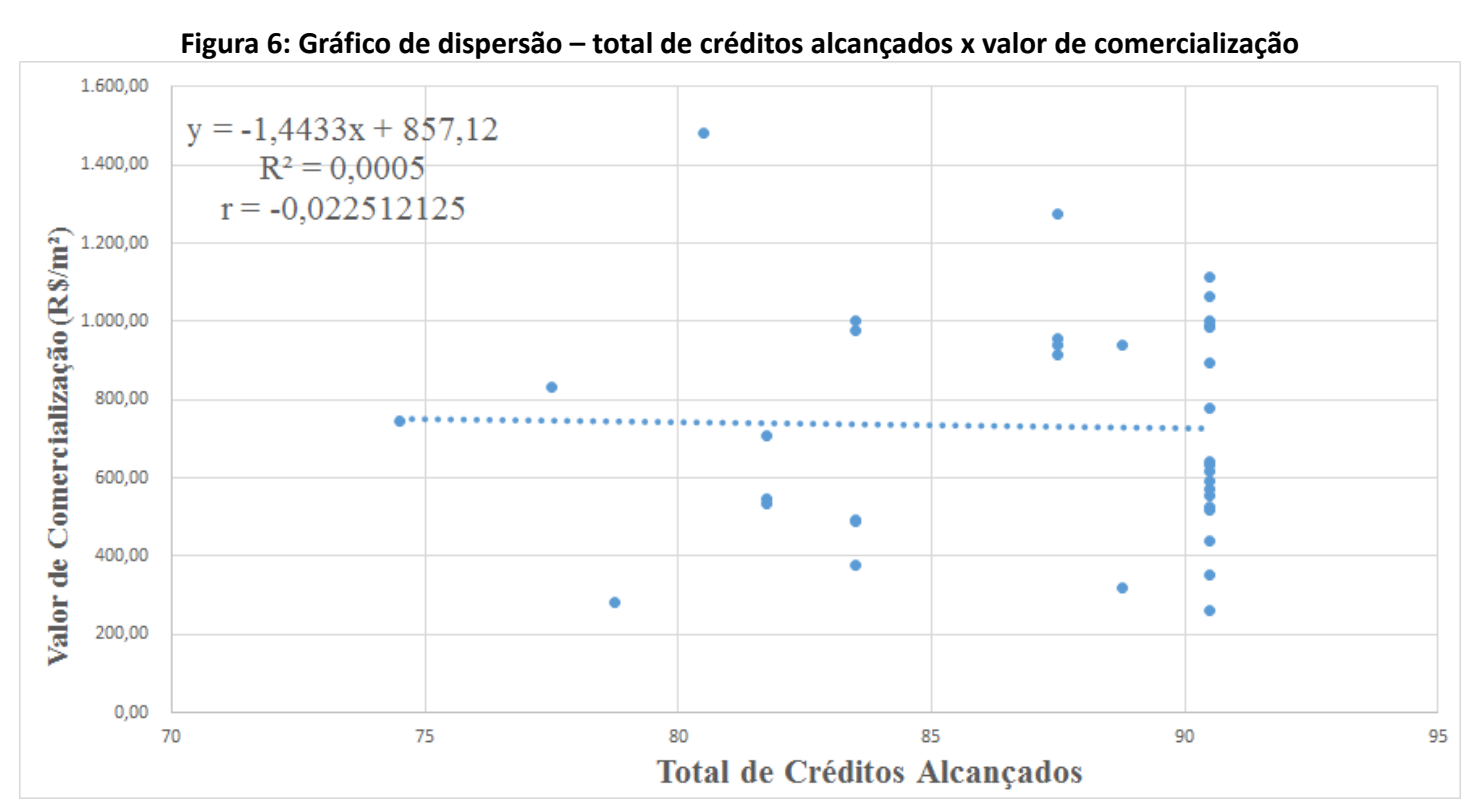

Fonte: Autores, 2020. 

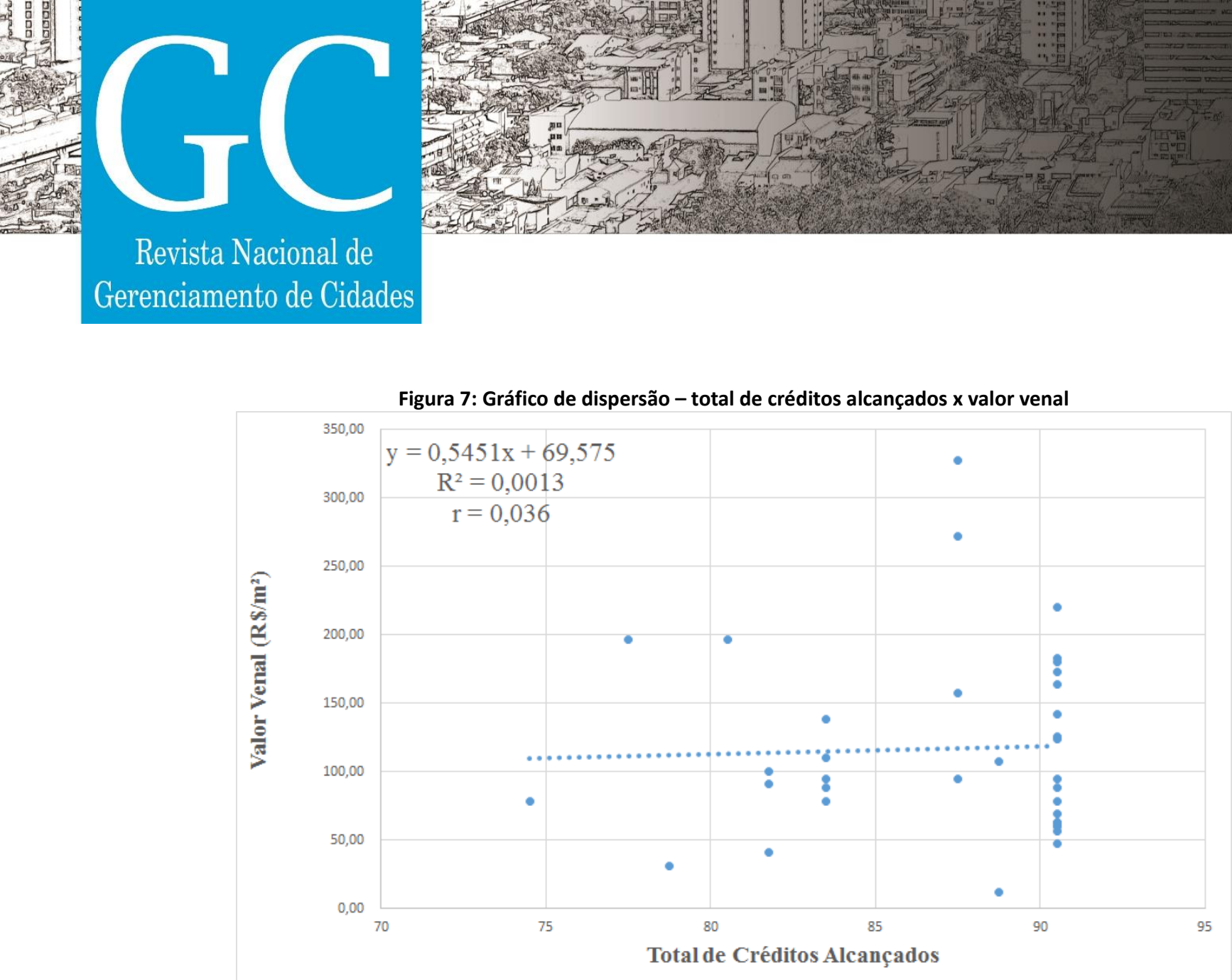

Fonte: Autores, 2020.

A partir da análise das Figuras 6 e 7, é possível verificar que em nenhum dos casos existe correlação entre as variáveis, já que o valor do coeficiente de correlação $(r)$ e do coeficiente de determinação $\left(R^{2}\right)$ foram muito inferiores a 1 , demonstrando que existe uma correlação linear fraca em ambos os cenários. Dessa forma, é possível afirmar que as imobiliárias e a prefeitura municipal podem não estar considerando os fatores sustentáveis inerentes aos lotes residenciais como um dos principais condicionantes para o processo de formação do preço dos lotes, uma vez que o nível de correlação entre as variáveis total de créditos alcançados e os valores de comercialização e venais foram fracos. Todavia, ainda é necessário se realizar uma análise mais aprofundada do método de definição dos preços de venda utilizado pelas imobiliárias e pela prefeitura.

\section{CONCLUSÃO}

Com a realização do presente trabalho foi possível avaliar um conjunto de lotes destinados à habitação unifamiliar da cidade de Maringá - PR, sob a perspectiva da sustentabilidade ambiental, sendo que para isso foi previamente elaborada uma ferramenta de avaliação construída a partir da opinião de especialistas.

Os indicadores e critérios vinculados ao sistema de avaliação desenvolvido foram baseados nas certificações LEED, Selo Casa Azul e Processo AQUA, além das publicações de Azouz e Galal (2016) e Kosanović e Fikfak (2016). Os critérios foram definidos considerando-se a realidade da 


\section{Revista Nacional de}

Gerenciamento de Cidades

cidade de Maringá - PR, as opiniões dos especialistas e a natureza dos dados disponíveis para a pesquisa.

Para realizar a avaliação dos lotes, prevista neste estudo, foi estabelecida uma amostra composta por 36 lotes não edificados, com dimensões suficientes para acomodar edificações residenciais unifamiliares, os quais abrangem todas as zonas fiscais dentro do perímetro urbano da cidade de Maringá - PR. A partir dos dados coletados e análises realizadas, concluiu-se que metade dos lotes analisados obtiveram o mesmo número de créditos previstos no sistema de avaliação. Além disso, também se constatou que o total de créditos atribuídos aos lotes no sistema de avaliação proposto não se correlaciona com seus respectivos valores de comercialização e venais. Assim, há indícios de que as imobiliárias e a prefeitura municipal não consideram os aspectos relacionados à sustentabilidade, relacionados com a presente pesquisa, como um dos fatores primordiais no processo de definição desses valores.

Dessa forma, verificou-se que a premissa levantada por Zavadskas et al. (2017) - de que a sustentabilidade no passado não era um dos fatores de maior relevância para a avaliação imobiliária de empreendimentos - pode ser considerada ainda válida para o cenário das empresas atuantes no segmento imobiliário na cidade de Maringá - PR, porém é necessário avaliar de maneira mais aprofundada o método de definição dos preços de comercialização praticado por essas empresas.

Para trabalhos futuros sugere-se aplicar o sistema de avaliação proposto em outras cidades e também que sejam expandidos os critérios contemplados no sistema de avaliação desenvolvido nesta pesquisa.

\section{AGRADECIMENTOS}

O presente trabalho foi realizado com apoio da Coordenação de Aperfeiçoamento de Pessoal de Nível Superior - Brasil (CAPES) - Código de Financiamento 001.

\section{REFERÊNCIAS BIBLIOGRÁFICAS}

AWADH, O. Sustainability and green building rating systems: LEED, BREEAM, GSAS and Estidama critical analysis. Journal of Building Engineering, v. 11, p. 25-29, 2017.

AZOUZ, M.; GALAL, A. Sustainable Site Assessment: A way to Sustainable Hospitality in Egypt. Procedia Environmental Sciences, v. 34, p. 360-374, 2016.

BRASIL. Lei Federal N 12.651, de 25 de maio de 2012. Dispõe sobre a proteção da vegetação nativa. Diário Oficial [da] República Federativa do Brasil, Poder Executivo, Brasília, DF, 2012.

CORPO DE BOMBEIROS DO PARANÁ. Sistema de Registro e Estatística de Ocorrência. 2018. Disponível em: <http://www.bombeiroscascavel.com.br/sysbmnew/menu imprensa/>. Acesso em: 01 ago. 2018.

ELKINGTON, J. Canibais com garfo e faca: seria um sinal de progresso se um canibal utilizasse garfo e faca para comer? São Paulo: Makron Books, 2011. 
